\title{
Prevalence and associated factors of internet addiction among young adults in Bangladesh
}

\author{
Tubayesha Hassan ${ }^{1,2}$, Mohammad Morshad Alam ${ }^{3,4^{*}}$ D, Abrar Wahab ${ }^{2}$ and Mohammad Delwer Hawlader ${ }^{2}$
}

\begin{abstract}
Background: In the last decades, the use of internet has increased many folds, and internet addiction has become a severe public health issue around the world. This study aimed to determine the prevalence of internet addiction among young adults (19-35 years) in Bangladesh and to identify factors associated with it.

Methods: A total of 454 participants were selected from three administrative divisions of Bangladesh using multistage cluster sampling for this cross-sectional study. A self-reported questionnaire was used to collect data which included Young's 20 items internet addiction test to assess internet addiction.

Results: The overall prevalence of internet addiction was $27.1 \%$. Addiction rate was $28.6 \%$ in the subgroup 19-24 years and $23.5 \%$ among 25-35 years old. In both chi-square and logistic regression analyses, internet addiction was significantly associated with living setup, time spent daily on the internet, a detached family relationship, physical activity, and smoking habit $(p<0.05)$. Spending time on social media websites was the most common online activity among the participants.

Conclusion: Our study revealed a relatively high prevalence of internet addiction among younger participants. A detached family relationship and living away from the family were significant determinants along other factors. Therefore, it is important to raise awareness among young generation and their parents towards predictors of internet addiction.
\end{abstract}

Keywords: Bangladesh, Cell phone, Internet addiction, Social media, Young adult

\section{Introduction}

In the present world, the Internet has become an unseparated part of everyday life. The number of internet users, as well as using hours, has grown exponentially among educated people because it is the most appropriate tool for worldwide communication, information source, and a broader source of entertainment [1]. Kimberly Young was the first to introduce the concept of internet addiction disorder (IAD) in 1996 [2], and she recommended including it in the Diagnostic and Statistical Manual of Mental Disorders (DSM), 4th ed [3]. However, the presence of internet addiction (IA) as a mental disorder has not yet been adequately recognized. The Diagnostic and Statistical

\footnotetext{
* Correspondence: mohammad.alam01@northsouth.edu

${ }^{3}$ Health, Nutrition and Population Global Practice, The World Bank, Agargaon, Dhaka 1207, Bangladesh

${ }^{4}$ Graduex Research Group, Dhaka 1209, Bangladesh

Full list of author information is available at the end of the article
}

Manual of Mental Disorders (DSM-5) mentioned that to be considered as a full disorder IAD requires more research. The negative consequences of IAD are visible in daily functioning, family relationship, and social life [4].

Internet addiction is typically described as a state where an individual has lost control of the internet use and keeps using internet excessively to the point where he/she experiences problematic outcomes that negatively affects life [5]. IA is characterized by a maladaptive pattern of internet use leading to clinically significant impairment or distress [6]. Most of the researches identified IA as the use of the internet in a way that creates difficulties in personal life [7]. There has been significant correlation of internet addiction with psychological and interpersonal problems such as inability to relate to other people, loss of control on own behavior, withdrawal from social activities, 
difficulty to maintain a regular time schedule, and disturbance of sleep and decline in sleep hours [8-10].

In the last decade, there was a nearly sixfold increase in internet usage worldwide, and about $40 \%$ of the world is in touch of the internet [11]. In a recent study [12], Xin et al. showed that studies on IA have reported variations in prevalence world-wide. In Europe and the USA, rates ranged from 7.9 to $25.2 \%$ among adolescents (2012) while the Middle East and Africa had rates from 17.3 to $23.6 \%$. Studies in Asia have shown a higher variation in prevalence among young people and adolescents, ranging from 8.1 to $50.9 \%$.

In a developing country like Bangladesh, it is necessary to determine the prevalence of internet addiction and identify its associated factors. With the government's substantial efforts to implement digital technology and revolutionize life on a mass scale, access to the internet is higher than ever. As a result, the number of internet users has increased significantly. The overall figure of internet subscribers has reached 83.141 million at the end of February 2018 which is around $50 \%$ of overall population. Among them, 77.495 million are mobile internet subscribers [13]. Although the numbers are justifiable at present, this may turn into a problem for our young-adult population in the future. It is widely known that young adults are the most active internet users worldwide, as they spend approximately $3 \mathrm{~h}$ online per day. This overuse is creating various negative impacts which are progressively emerging. The situation has led to significantly increased response against overuse of the internet and its negative consequences all over the world [14].

Most of the studies conducted previously evaluated the prevalence of internet addiction and its predictors in adolescent samples, within the age range of 12 to 18 years. Studies targetting young adults, who are also a high-risk group of internet addiction, are very much limited. Our study aimed to determine the prevalence of internet addiction among the young-adult population and to reveal the associated factors behind internet addiction in Bangladesh.

\section{Methods}

\subsection{Study design and tools}

This cross-sectional study was conducted in three administrative divisions (Dhaka, Chittagong, and Sylhet) of Bangladesh during the months of January to April of 2018. Young's 20-item Internet Addiction Scale was used to determine the presence or absence of addiction. A validated Bengali version of the instrument [15] and questionnaire was used to collect information from respondents which were pretested among $5 \%$ of the sample population prior to data collection. This widely used instrument has been scientifically analyzed to state an ambiguous psychometric factor structure: salience, lack of control, negligence, time management, etc. Because of the strong correlation among these psychometric factors, it has been considered a robust tool for this study.

To assess behavioral factors, questions were included about the use of internet (length of use, frequency of use, device for use, presence of computer in residence, type of software or application use, type of internet service use, purpose of internet use) and community variables (internet use of friends or colleagues, influence of surrounding people on internet use, influence of surrounding people on internet use). The sociodemographic factors included age, sex, occupation, arrangement of accommodation, area of residence, monthly family income, and personality type. Students were asked to answer questions about family variables (supervision of parents during internet use, problems in family relation, internet use of family members). Cut-off points were marked to categorize the presence of internet addiction. If a respondent got 20-49 points at the scale of 100 points, he was considered an average on-line user. On the other hand, a respondent who scored $\geq 50$ points was considered as internet addicted $[15,16]$.

\subsection{Sample size}

To estimate the sample size, a single population proportion formula was used. Several previous studies conducted in various locations found the prevalence of internet addiction was around $18 \%[17,18]$. Considering those reference, the required sample size was $n=227$ when the allowable error was 5\%. Using a design effect 2 , the final sample size was 454 .

\subsection{Sampling and data collection}

A multistage clustered sampling was used. From the 3 administrative divisions, 28 districts were targeted, from which three districts (1 from each division) were randomly selected. From each district, two subdistricts were chosen randomly, and finally, households were conveniently selected for data collection. A total of 454 participants were selected (247 males and 207 females). The participants were young adults, internet users, aged between 19 and 35 years. They were categorized according to age, 318 individuals in group A (age 19-24 years) and 136 individuals in group B (age 25-35 years). A Bengali version of questionnaire was filled up by the participants, the first part of which consisted of socio-demographic information and the second part included Young's 20item internet addiction test. Participants who did not want to participate were excluded from this study.

\subsection{Statistical analysis}

Data were checked for completeness and consistency. IBM SPSS version 23 statistical package software was used for data management and analysis. Various 
descriptive statistics like frequencies and proportions were calculated. Degrees of association between the outcome variable and independent variables were determined by the chi-square test. Variables that showed significant association in chi-square analysis were subjected to multiple logistic regression analyses to explore the strength of association. Results with $p$ values of $<0.05$ were considered to be statistically significant.

\subsection{Ethics approval and consent to participate}

Ethical approval for this research protocol was obtained from the Ethics Review Committee of North South University prior to data collection (no. 0013/2018). The aims of the investigation and the nature of the study were fully explained to the participants, who gave informed written consent before participation.

\section{Results}

Of the total 454 respondents, 123 (27.1\%) were addicted to the internet (Fig. 1).

Most of the participants, $318(70.0 \%)$ were between the age of $19-24$ years and $331(72.9 \%)$ of total participants were students. Among the participants, 170 (74.2\%) came from the urban area and $34(7.5 \%)$ had a history of family relationship detachment (Table 1).

On the other hand, 134 (29.5\%) had the habit of smoking (current smoker), most participants (86.8\%) were using the internet for more than a year, and $66.5 \%$ user used the internet on their mobile phones. Social websites were determined most popular among internet users, and a large number of users (35.2\%) liked to stay on the internet for more than $3 \mathrm{~h}$ a day (Table 2).

Addiction rate was $28.62 \%$ in the subgroup 19-24 years and $23.53 \%$ in the subgroup $25-35$ years. Internet addiction was significantly associated with sex $(p=0.019)$, living setup ( $p=0.012)$, smoking habit $(p<0.01)$, recommended amount of physical activity $(p<0.01)$, length of internet use $(p=0.025)$, device used to use internet $(p=$ $0.027)$, time spent daily on the internet $(p=0.00)$, family relation detachment $(p<0.01)$, and overuse of internet among family members $(p=0.011)$ (Table 3$)$.

On the other hand, our adjusted analysis indicated that persons who lived with family members were less likely to be addicted (AOR $=0.313,95 \%$ CI $0.17-0.65$ ) in comparison to those who live without family members. The gender of respondents became insignificant in logistic regression model. Participants who spent less time on the internet were also less likely to become addicted to the internet. Moreover, persons who had a good relationship with family members were less prone to be addicted (AOR $=0.098,95 \%$ CI $0.04-0.28$ ) to the internet. Physical activity and smoking habit both were found as potential predictors of internet addiction. Other significant variables in the chi-square analysis such as length of using internet, device used, and overuse of internet among family members did not show statistically significant association with internet addiction in logistic regression model (Table 4).

\section{Discussion}

Our research sought to determine the prevalence of internet addiction among young adults of different locations of Bangladesh. Besides, the study also looked for the association between internet addiction and different sociodemographic and internet-usage-related variables.

Our study revealed that the overall prevalence of IA is $27.1 \%$, which is close to a study previously conducted in Bangladesh [19]. The prevalence rates of internet addiction varied across different sociodemographic and internet-use related variables. The current rate (27.1\%) was lower than the rates obtained in different Middle

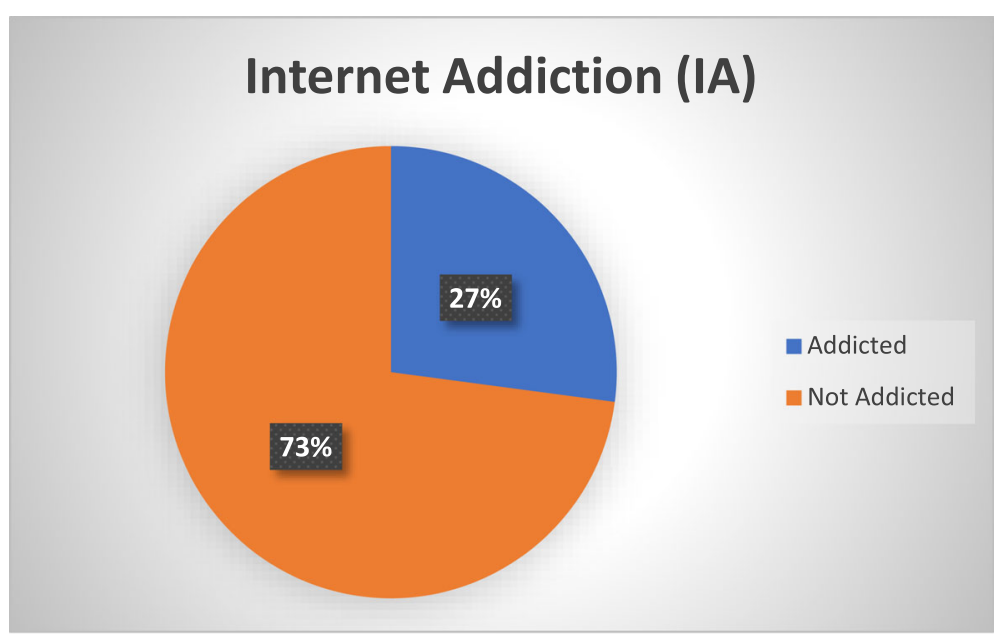

Fig. 1 Prevalence of internet addiction among young adults in Bangladesh, 2018 
Table 1 Sociodemographic characteristics of young adult internet users in Bangladesh, 2018

\begin{tabular}{|c|c|c|}
\hline Variables with categories & Frequency (No.) & Percent (\%) \\
\hline \multicolumn{3}{|l|}{ Age } \\
\hline 19-24 years & 318 & 70.0 \\
\hline $25-35$ years & 136 & 30.0 \\
\hline \multicolumn{3}{|l|}{ Sex } \\
\hline Female & 207 & 45.6 \\
\hline Male & 247 & 54.4 \\
\hline \multicolumn{3}{|l|}{ Occupation } \\
\hline Housewife & 17 & 3.8 \\
\hline Service & 96 & 21.1 \\
\hline Other & 10 & 2.2 \\
\hline Student & 331 & 72.9 \\
\hline \multicolumn{3}{|l|}{ Father's occupation" ${ }^{\#}$} \\
\hline Business & 133 & 29.3 \\
\hline Farmer & 38 & 8.4 \\
\hline Service & 180 & 39.6 \\
\hline Other & 38 & 8.4 \\
\hline \multicolumn{3}{|l|}{ Mother's occupation" } \\
\hline Business & 5 & 1.1 \\
\hline Housewife & 377 & 83.0 \\
\hline Job & 28 & 6.2 \\
\hline \multicolumn{3}{|l|}{ Living setup } \\
\hline Family members & 307 & 67.6 \\
\hline Others (Mess, hostel) & 147 & 32.4 \\
\hline \multicolumn{3}{|c|}{ Monthly family income (in taka) } \\
\hline$<20,000$ & 50 & 11.0 \\
\hline $20,000-40,000$ & 154 & 33.9 \\
\hline$>40,000$ & 250 & 55.1 \\
\hline \multicolumn{3}{|l|}{ Place of residence } \\
\hline Rural & 44 & 9.7 \\
\hline Semi-urban & 74 & 16.3 \\
\hline Urban & 336 & 74.0 \\
\hline \multicolumn{3}{|l|}{ Having own computer } \\
\hline No & 181 & 39.9 \\
\hline Yes & 273 & 60.1 \\
\hline \multicolumn{3}{|c|}{ Family relationship detachment } \\
\hline No & 420 & 92.5 \\
\hline Yes & 34 & 7.5 \\
\hline \multicolumn{3}{|c|}{ Overuse of internet among family members } \\
\hline No & 321 & 70.7 \\
\hline Yes & 133 & 29.3 \\
\hline \multicolumn{3}{|c|}{ Peers /workplace encouragement } \\
\hline No & 269 & 59.3 \\
\hline Yes & 185 & 40.7 \\
\hline
\end{tabular}

\#65 fathers and 44 mothers got retirement or dead
Table 2 Activity related characteristics of the young adult internet users of Bangladesh, 2018

\begin{tabular}{|c|c|c|}
\hline Variables with categories & Frequency (No.) & Percent (\%) \\
\hline \multicolumn{3}{|c|}{ Recommended amount of physical activity ${ }^{+}$} \\
\hline No & 186 & 41.0 \\
\hline Yes & 268 & 59.0 \\
\hline \multicolumn{3}{|l|}{ Current smoker } \\
\hline No & 320 & 70.5 \\
\hline Yes & 134 & 29.5 \\
\hline \multicolumn{3}{|l|}{ Length of internet use } \\
\hline$<6$ months & 34 & 7.5 \\
\hline 6-12 months & 26 & 5.7 \\
\hline$>12$ months & 394 & 86.8 \\
\hline \multicolumn{3}{|c|}{ Device used to use the internet } \\
\hline Computer & 48 & 10.6 \\
\hline Mobile phone & 302 & 66.5 \\
\hline Both & 104 & 22.9 \\
\hline \multicolumn{3}{|l|}{ Daily internet use duration } \\
\hline$<1 \mathrm{~h}$ & 62 & 13.7 \\
\hline $1-<2 \mathrm{~h}$ & 117 & 25.8 \\
\hline $2-<3 h$ & 115 & 25.3 \\
\hline 3 or $3+h$ & 160 & 35.2 \\
\hline \multicolumn{3}{|l|}{ Most used app/website } \\
\hline Social & 247 & 54.4 \\
\hline Mailing & 89 & 19.6 \\
\hline Online video & 68 & 15.0 \\
\hline Internet gaming & 34 & 7.5 \\
\hline Other & 16 & 3.5 \\
\hline
\end{tabular}

${ }^{+}$At least $150 \mathrm{~min}$ of moderate aerobic activity or $75 \mathrm{~min}$ of vigorous aerobic activity in a week

East countries like Jordan (40\%) [20] and Iran (39.6\%) [21] but relatively higher than the studies conducted among British (18.3\%) [22] and Taiwanese samples (17.4\%) [23]. Besides cultural factors, these differences may be attributed to variations in the diagnostic criteria and assessment questionnaires used for diagnosis. In addition, studies often use highly selective samples of online surveys.

Males were more prone to internet addiction (31.58\%) than female $(21.74 \%)$, which corresponds with previous literatures $[12,24]$. It may be because males are generally more passionate regarding knowing the unknown or exploring new inventions or they are usually more attracted to addictive objects such as pornography, cybersex, and online gaming compared with the female [24-26].

Family economic status was revealed as an important determinant of internet addiction in our adjusted model, a good economic condition was found to be inversely associated with internet addiction. A previous Greek study 
Table 3 Association of socio-demographic and activity related characteristics of internet users with internet addiction

\begin{tabular}{|c|c|c|c|c|}
\hline Variables with category & Addicted (\%) & Not addicted (\%) & Chi-square & $P$ value \\
\hline$\overline{\text { Age }}$ & & & 1.25 & 0.27 \\
\hline 19-24 years & $91(28.62)$ & $227(71.38)$ & & \\
\hline $25-35$ years & $32(23.53)$ & $104(76.47)$ & & \\
\hline Sex & & & 5.520 & $0.02^{*}$ \\
\hline Male & $78(31.58)$ & $169(68.42)$ & & \\
\hline Female & $45(21.74)$ & $162(78.26)$ & & \\
\hline Occupation & & & 4.968 & 0.17 \\
\hline Housewife & $1(5.88)$ & $16(94.12)$ & & \\
\hline Job & $30(31.25)$ & $66(68.75)$ & & \\
\hline Student & $90(27.19)$ & $241(72.81)$ & & \\
\hline Others & $2(20.00)$ & $8(80.00)$ & & \\
\hline Father's occupation & & & 5.004 & 0.29 \\
\hline Business & $45(33.83)$ & $88(66.17)$ & & \\
\hline Farmer & $8(21.05)$ & $30(78.95)$ & & \\
\hline Job & $46(25.56)$ & $134(74.44)$ & & \\
\hline Others & $10(26.32)$ & $28(73.68)$ & & \\
\hline Mother's occupation & & & 4.028 & 0.26 \\
\hline Business & $3(60.00)$ & $2(40.00)$ & & \\
\hline Housewife & $98(25.99)$ & $279(74.01)$ & & \\
\hline Job & $10(35.71)$ & $18(64.29)$ & & \\
\hline Living setup & & & 6.359 & $0.01^{*}$ \\
\hline Family members & $72(23.45)$ & $235(76.55)$ & & \\
\hline Others (mess, hostel) & $51(34.69)$ & $96(65.31)$ & & \\
\hline Monthly family income (Taka) & & & 4.824 & 0.09 \\
\hline$<20,000$ & $20(40.00)$ & $30(60.00)$ & & \\
\hline $20,000-40,000$ & $38(24.68)$ & $116(75.32)$ & & \\
\hline$>40,000$ & $65(26.00)$ & $185(74.00)$ & & \\
\hline Place of residence & & & 0.785 & 0.68 \\
\hline Rural & $14(31.82)$ & $30(68.18)$ & & \\
\hline Semi-urban & $18(24.32)$ & $56(75.68)$ & & \\
\hline Urban & $91(27.08)$ & $245(72.92)$ & & \\
\hline Smoking (current smoker) & & & 38.201 & $<0.01^{*}$ \\
\hline No & $60(18.75)$ & $260(81.25)$ & & \\
\hline Yes & $63(47.01)$ & $71(52.99)$ & & \\
\hline Recommended amount of physical activity & & & 11.233 & $<0.01^{*}$ \\
\hline No & $66(35.48)$ & $120(64.52)$ & & \\
\hline Yes & $57(21.27)$ & $211(78.73)$ & & \\
\hline Length of using the internet & & & 7.366 & $0.03^{*}$ \\
\hline$<6$ months & $6(17.65)$ & $28(82.35)$ & & \\
\hline 6-12 month & $2(7.69)$ & $24(92.31)$ & & \\
\hline$>1$ year & 115 (29.19) & $279(70.81)$ & & \\
\hline Having computer & & & 0.429 & 0.51 \\
\hline No & $46(25.41)$ & 135 (74.59) & & \\
\hline Yes & 77 (28.21) & $196(71.79)$ & & \\
\hline
\end{tabular}


Table 3 Association of socio-demographic and activity related characteristics of internet users with internet addiction (Continued)

\begin{tabular}{|c|c|c|c|c|}
\hline Variables with category & Addicted (\%) & Not addicted (\%) & Chi-square & $P$ value \\
\hline Device where internet is used & & & 7.223 & $0.03^{*}$ \\
\hline Mobile/tab & $35(22.58)$ & $120(77.42)$ & & \\
\hline Computer & $50(25.38)$ & $147(74.62)$ & & \\
\hline Both & $38(37.25)$ & $64(62.75)$ & & \\
\hline Time spent daily on the internet & & & 67.699 & $<0.01^{*}$ \\
\hline$<1 \mathrm{~h}$ & $6(9.68)$ & $56(90.32)$ & & \\
\hline $1-<2 h$ & $12(10.26)$ & $105(89.74)$ & & \\
\hline $2-<3 h$ & $26(22.61)$ & $89(77.39)$ & & \\
\hline 3 or $3+h$ & 79 (49.38) & $81(50.63)$ & & \\
\hline App/web most commonly used & & & 4.227 & 0.38 \\
\hline Social media & $69(27.94)$ & $178(72.06)$ & & \\
\hline Emailing & $19(21.35)$ & $70(78.65)$ & & \\
\hline Online video & $20(29.41)$ & $48(70.59)$ & & \\
\hline Gaming & $8(23.53)$ & $26(76.47)$ & & \\
\hline Others & $7(43.75)$ & $9(56.25)$ & & \\
\hline Family relation detachment & & & 7.418 & $<0.01^{*}$ \\
\hline No & $107(25.48)$ & $313(74.52)$ & & \\
\hline Yes & $16(47.06)$ & $18(52.94)$ & & \\
\hline Overuse of internet among family members & & & 6.475 & $0.01^{*}$ \\
\hline No & $76(23.68)$ & $245(76.32)$ & & \\
\hline Yes & $47(35.34)$ & $86(64.66)$ & & \\
\hline Peers/workplace encouragement & & & 3.641 & 0.06 \\
\hline No & $64(23.79)$ & $205(76.21)$ & & \\
\hline Yes & $59(31.89)$ & $126(68.11)$ & & \\
\hline
\end{tabular}

*Statistically significant association at $p<0.05$

and a study conducted in Bangladesh, 2016, were also in line with these study findings $[19,27]$. Increased online engagement is also significantly associated with internet addiction; this online engagement, if not controlled, could appear as problematic, and it is supported by previously conducted studies $[28,29]$.

On the other hand, people living with family members usually get more time to spend with family members which ultimately gives them support against problematic use of the internet. In our analysis, living setup was found as a strong determinant in our adjusted regression and chi-square analysis.

Internet addiction was also found to be more common among those who had a family relationship detachment. Previously conducted researches also suggest that breakdown of a close relationship is associated with poor mental health by growing gloominess and defeating mentality, which might manifest addictive behaviors as a consequence [30, 31]. Internet addiction was also significantly higher among respondents who had a smoking habit or did not involve in a considerable amount of physical activity.

\subsection{Strengths and limitations}

The target population of this study was young adults from various regions of Bangladesh whereas previously conducted studies in Bangladesh targeted students of a single region. Also, our study included a considerably high number of sociodemographic variables as well as variables related to internet use behavior and regular activity. Our study also revealed living setup as a significant predictor of internet addiction. This is distinctive in cyberpsychology research in Bangladesh.

There are several limitations as this study is crosssectional; therefore, no causal relationships were explored. There was a possibility of response-related biases because data were self-reported. Moreover, study participants were conveniently selected for the interview, which may increase potential confounding effects. Despite these limitations, this study had determined the prevalence of IA and investigated the associated factors from a representative sample of several locations in Bangladesh. 
Table 4 Multiple logistic regression analysis of variables associated with internet addiction in Bangladesh

\begin{tabular}{|c|c|c|c|}
\hline $\begin{array}{l}\text { Variables with } \\
\text { category }\end{array}$ & Estimate & $\begin{array}{l}\text { Adjusted odds ratio } \\
(95 \% \mathrm{Cl})\end{array}$ & $P$ value \\
\hline \multicolumn{3}{|l|}{ Sex } & 0.08 \\
\hline Male & 0.70 & $2.031(0.89-4.61)$ & 0.08 \\
\hline Female & Reference & Reference & Reference \\
\hline \multicolumn{3}{|l|}{ Living setup } & $<0.01^{*}$ \\
\hline Family members & -1.182 & $0.313(0.17-0.65)$ & 0.002 \\
\hline Others (mess, hostel) & Reference & Reference & Reference \\
\hline \multicolumn{3}{|c|}{ Length of using the internet } & 0.27 \\
\hline$<6$ months & -0.623 & $0.622(0.14-3.21)$ & 0.54 \\
\hline 6-12 month & -1.546 & $0.236(0.04-1.56)$ & 0.15 \\
\hline$>1$ year & Reference & Reference & Reference \\
\hline \multicolumn{3}{|c|}{ Device where internet is used } & 0.43 \\
\hline Mobile/tab & -0.515 & $0.613(0.26-1.43)$ & 0.31 \\
\hline Computer & -0.208 & $0.824(0.36-1.92)$ & 0.52 \\
\hline Both & Reference & Reference & Reference \\
\hline \multicolumn{3}{|c|}{ Time spent daily on the internet } & $<0.01^{*}$ \\
\hline$<1 \mathrm{~h}$ & -3.514 & $0.033(0.01-0.13)$ & 0.00 \\
\hline $1-<2 \mathrm{~h}$ & -2.810 & $0.067(0.03-0.17)$ & 0.00 \\
\hline $2-<3 h$ & -1.622 & $0.214(0.11-0.43)$ & 0.00 \\
\hline 3 or $3+h$ & Reference & Reference & Reference \\
\hline \multicolumn{3}{|c|}{ Family relation detachment } & $<0.01^{*}$ \\
\hline No & -2.328 & $0.098(0.04-0.28)$ & 0.00 \\
\hline Yes & Reference & Reference & Reference \\
\hline \multicolumn{3}{|c|}{ Overuse of internet among family members } & 0.51 \\
\hline No & -0.228 & $0.796(0.403-1.571)$ & 0.51 \\
\hline Yes & Reference & Reference & Reference \\
\hline \multicolumn{3}{|c|}{ Recommended amount physical activity } & $<0.01^{*}$ \\
\hline No & 1.12 & $2.87(1.65-5.08)$ & 0.00 \\
\hline Yes & Reference & Reference & Reference \\
\hline \multicolumn{3}{|l|}{ Smoking (current smoker) } & $<0.01^{*}$ \\
\hline No & -1.41 & $0.26(0.13-0.58)$ & 0.001 \\
\hline Yes & Reference & Reference & Reference \\
\hline
\end{tabular}

*Statistically significant association $(p<0.05)$

\section{Conclusion}

The prevalence of excessive internet use is significant among young adults in Bangladesh, which is conforming with the global trend. There are a number of determinants that have the potential to point out to a much alarming situation. For example, a detached family relationship and smoking habit are strong predictors for internet addiction. Moreover, living setup, time spent daily on the internet, and physical activity level were also significantly associated with internet addiction. As the sample of this study is considerably small, it is insufficient to conclude that internet addiction is high among
Bangladeshi young adults. So, further studies using a larger sample size are necessary for proper assessment of the internet addiction situation in Bangladesh. Nonetheless, early awareness is important for the policymakers in order to examine the problem and implement effective measures to prevent it.

\section{Acknowledgements}

Not applicable

\section{Authors' contributions}

$\mathrm{TH}$ and MMA equally contributed to the research design, data collection and extraction, analysis, and manuscript preparation. MDHH supervised the study and revised the manuscript. AW helped in drafting the manuscript. All authors read and approved the manuscript.

\section{Funding}

This research did not receive any funding from any agency in the public, commercial, or not-for-profit sectors.

\section{Availability of data and materials}

The datasets used in the current study is available from the corresponding author on reasonable request.

\section{Ethics approval and consent to participate}

Ethical approval for research protocol was obtained from the Ethics Review Committee of North South University prior to data collection (no. 0013/2018; Date: January 19, 2018). A written informed consent was obtained from each of the study participants.

\section{Consent for publication}

Not applicable.

\section{Competing interests}

The authors declare that they have no competing interests.

\section{Author details}

'School of Dentistry, Health Sciences University of Hokkaido, Tobetsu, Ishikari 061-0233, Japan. ²Department of Public Health, North South University, Dhaka 1229, Bangladesh. ${ }^{3}$ Health, Nutrition and Population Global Practice, The World Bank, Agargaon, Dhaka 1207, Bangladesh. ${ }^{4}$ Graduex Research Group, Dhaka 1209, Bangladesh.

Received: 28 April 2019 Accepted: 17 December 2019

Published online: 29 January 2020

References

1. Anderson EL, Steen E, Stavropoulos V. Internet use and problematic internet use: a systematic review of longitudinal research trends in adolescence and emergent adulthood. Int J Adolesc Youth. 2017;22(4):430-54.

2. Young KS. Internet addiction: the emergence of a new clinical disorder. CyberPsychology Behav. 1996;1(3):237-44.

3. Cooper J. Diagnostic and Statistical Manual of Mental Disorders (4th ed, text revision) (DSM-IV-TR) Washington. DC: American Psychiatric Association; 2000. 943 pp.

4. American Psychiatric Association. Diagnostic and Statistical Manual Of Mental Disorders (DSM-5). American Psychiatric Pub. 2013 May 22.

5. Young KS, De Abreu CN, editors. Internet addiction: a handbook and guide to evaluation and treatment. John Wiley \& Sons; 2010.

6. Weinstein A, Lejoyeux M. Internet addiction or excessive internet use. Am J Drug Alcohol Abuse. 2010;36(5):277-83.

7. Diomidous M, Chardalias K, Magita A, Koutonias P, Panagiotopoulou P, Mantas J. Social and psychological effects of the internet use. Acta Inform Medica. 2016;24(1):66-9.

8. Alam SS, Hazrul NM, Hashim N, Ahmad M, Aniza C, Wel C, et al. Negative and positive impact of internet addiction on young adults: empericial study in Malaysia. Intang Cap. 2014;10(3):619-38.

9. Akın A. The relationships between internet addiction, subjective vitality, and subjective happiness. Cyberpsychology, Behav Soc Netw. 2012;15(8):404-10. 
10. Morrison $\mathrm{CM}$, Gore $\mathrm{H}$. The relationship between excessive internet use and depression: a questionnaire-based study of 1,319 young people and adults. Psychopathology. 2010;43(2):121-6.

11. International Telecommunication Union (ITU). ICT facts and figures - the world in 2013 [Internet]. 2013. 8 p. http://www.itu.int/en/TU-D/Statistics/ Documents/facts/ICTFactsFigures2013.pdf

12. Xin M, Xing J, Pengfei W, Houru L, Mengcheng W, Hong Z. Online activities, prevalence of Internet addiction and risk factors related to family and school among adolescents in China. Addict Behav Rep. 2017;7:14-8.

13. Bangladesh Telecommunication Regulatory Commission (BTRC). Internet Subscribers. http://www.btrc.gov.bd/content/internetsubscribers-bangladesh 2018.

14. Cao H, Sun Y, Wan Y, Hao J, Tao F. Problematic Internet use in Chinese adolescents and its relation to psychosomatic symptoms and life satisfaction. BMC Public Health. 2011:11(1):802.

15. Karim AR, Nigar $N$. The internet addiction test: assessing its psychometric properties in Bangladeshi culture. Asian J Psychiatr. 2014;10:75-83.

16. Widyanto L, McMurran M. The psychometric properties of the Internet Addiction Test. CyberPsychology Behav. 2004;7(4):443-50.

17. Lin M-P, Wu JY-W, You J, Hu W-H. Prevalence of internet addiction and its risk and protective factors in a representative sample of senior high school students in Taiwan. J Adolesc. 2018:62(1):38-46.

18. de Vries HT, Nakamae T, Fukui K, Denys D, Narumoto J. Problematic internet use and psychiatric co-morbidity in a population of Japanese adult psychiatric patients. BMC Psychiatry. 2018;1:9.

19. Islam MA, Hossin MZ. Prevalence and risk factors of problematic internet use and the associated psychological distress among graduate students of Bangladesh. Asian J Gambl Issues Public Health. 2016;6(1):11.

20. Al-Gamal E, Alzayyat A, Ahmad MM. Prevalence of internet addiction and its association with psychological distress and coping strategies among university students in Jordan. Perspect Psychiatr Care. 2016;52(1):49-61.

21. Ataee M, Ahmadi JT, Emdadi SH, Hatamzadeh N, Mahboubi M, Aghaei A. Prevalence of internet addiction and its associated factors in Hamadan University of medical college students. Life Sci J. 2014;11(spec. issue 4):214-7.

22. Niemz K, Griffiths M, Banyard P. Prevalence of pathological internet use among university students and correlations with self-esteem, the General Health Questionnaire (GHO) and disinhibition. CyberPsychology Behav, 2005:8(6):562-70.

23. Ha YM, Hwang WJ. Gender differences in internet addiction associated with psychological health indicators among adolescents using a national webbased survey. Int J Ment Health Addict. 2014;12(5):660-9.

24. Cypress VZ. Cybersexuality in MMORPGs: virtual sexual revolution untapped. Men and Masculinities. 2011;14(1):76-96.

25. Doornwaard SM, van Den Eijnden RJ, Baams L, Vanwesenbeeck I, Ter Bogt TF. Lower psychological well-being and excessive sexual interest predict symptoms of compulsive use of sexually explicit internet material among adolescent boys. J Youth Adolesc. 2016;45(1):73-84.

26. Bruno A, Scimeca G, Cava L, Pandolfo G, Zoccali RA, Muscatello MRA. Prevalence of internet addiction in a sample of Southern Italian high school students. Int J Ment Health Addict. 2014;12(6):708-15.

27. Andreou E, Svoli H. The Association between internet user characteristics and dimensions of internet addiction among Greek adolescents. Int J Ment Health Addict. 2013:11(2):139-48.

28. Caplan SE. Relations among loneliness, social anxiety, and problematic internet use. CyberPsychology Behav. 2007;10(2):234-42.

29. Kim J, Haridakis PM. The role of internet user characteristics and motives in explaining three dimensions of internet addiction. J Comput Commun. 2009:14:988-1015.

30. Liu C-Y, Kuo F-Y. A study of internet addiction through the lens of the interpersonal theory. CyberPsychology Behav. 2007:10(6):799-804.

31. Simon RW, Barrett AE. Nonmarital romantic relationships and mental health in early adulthood: does the association differ for women and men? J Health Soc Behav. 2010;51(2):168-82.

\section{Publisher's Note}

Springer Nature remains neutral with regard to jurisdictional claims in published maps and institutional affiliations.

\section{Submit your manuscript to a SpringerOpen ${ }^{\circ}$ journal and benefit from:}

- Convenient online submission

- Rigorous peer review

- Open access: articles freely available online

- High visibility within the field

- Retaining the copyright to your article

Submit your next manuscript at $\boldsymbol{\nabla}$ springeropen.com 